\title{
Genome sequence of the Ornithopus/Lupinus-nodulating Bradyrhizobium sp. strain WSM471
}

\author{
Wayne Reeve ${ }^{*}$, Sofie De Meyer ${ }^{1}$, Jason Terpolilli ${ }^{1}$, Vanessa Melino ${ }^{1}$, Julie Ardley ${ }^{1}$, Rui \\ Tian $^{1}$, Ravi Tiwari ${ }^{1}$, John Howieson ${ }^{1}$, Ronald Yates ${ }^{1,2}$, Graham $\mathrm{O}^{\prime}$ Hara $^{1}$, Mohamed Ninawi ${ }^{1}$, \\ Megan Lu ${ }^{3}$, David Bruce ${ }^{3}$, Chris Detter ${ }^{3}$, Roxanne Tapia ${ }^{3}$, Cliff Han $^{3}$, Chia-Lin Wei ${ }^{3}$, Marcel \\ Huntemann $^{3}$, James Han ${ }^{3}$, I-Min Chen ${ }^{5}$, Konstantinos Mavromatis ${ }^{3}$, Victor Markowitz ${ }^{5}$, \\ Natalia Ivanova ${ }^{3}$, Ioanna Pagani ${ }^{3}$, Amrita Pati ${ }^{3}$, Lynne Goodwin ${ }^{4}$, Tanja Woyke ${ }^{3}$ \& Nikos \\ Kyrpides ${ }^{3}$. \\ ${ }^{1}$ Centre for Rhizobium Studies, Murdoch University, Western Australia, Australia \\ 2 Department of Agriculture and Food, Western Australia, Australia \\ ${ }^{3}$ DOE Joint Genome Institute, Walnut Creek, California, USA \\ ${ }^{4}$ Los Alamos National Laboratory, Bioscience Division, Los Alamos, New Mexico, USA \\ ${ }^{5}$ Biological Data Management and Technology Center, Lawrence Berkeley National \\ Laboratory, Berkeley, California, USA
}

*Correspondence: Wayne Reeve (W.Reeve@murdoch.edu.au)

Keywords: root-nodule bacteria, nitrog en fixation, rhizobia, Alphaproteobacteria

\begin{abstract}
Bradyrhizobium sp. strain WSM471 is an aerobic, motile, Gram-negative, non-spore-forming rod that was isolated from an effective nitrogen- $\left(\mathrm{N}_{2}\right)$ fixing root nodule formed on the annual legume Ornithopus pinnatus (Miller) Druce growing at Oyster Harbour, Albany district, Western Australia in 1982. This strain is in commercial production as an inoculant for Lupinus and Ornithopus. Here we describe the features of Bradyrhizobium sp. strain WSM471, together with genome sequence information and annotation. The 7,784,016 bp high-quality-draft genome is arranged in 1 scaffold of 2 contigs, contains 7,372 proteincoding genes and 58 RNA-only encoding genes, and is one of 20 rhizobial genomes sequenced as part of the DOE Joint Genome Institute 2010 Community Sequencing Prog ram.
\end{abstract}

\section{Introduction}

The most abundant form of nitrogen (N) occurs in the atmosphere as a chemically inert dinitrogen $\left(\mathrm{N}_{2}\right)$ gas. However, $\mathrm{N}_{2}$ needs to be converted first into a biologically useable form through the unique process of $\mathrm{N}_{2}$ fixation [1]. The incorporation of fixed $\mathrm{N}$ into biologically essential macromolecules provides the basis for the continuance of life on Earth. Bioavailable N can be chemically synthesized (primarily through the products obtained from the Haber-Bosch process) or biologically fixed by $\mathrm{N}_{2}$-fixing diazotrophs. The highest contribution to biological fixation occurs from the process of symbiotic nitrogen fixation (SNF). The estimated total annual input from SNF ranges from 139 - 175 million tons [2] which provides $\sim 70 \%$ of the $\mathrm{N}$ currently utilized in agriculture. However, various constraints from edaphic conditions can limit SNF capacity in certain agricultural areas. To extend productive crops and pastures into these regions, considerable efforts have been devoted to sourcing legume hosts and their compatible microsymbionts from different geographical locations that are edaphically and climatically suited to the challenging areas into which they are to be introduced [3].

These selection programs have enabled the domestication of new Mediterranean legume species that have overcome the deficiencies of the use of traditional species [4]. Seven species new to Australian agriculture have been commercialized since 1993 including the Papilionoid legume Ornithopus sativus (serradella) [4]. This hardseeded deep-rooted and acid tolerant pasture legume has shown particular promise in acidic sandy soils exposed to low rainfall [4], with the potential to be established in four million hectares of sandy 
soils for which no other suitable legume pasture exists [5]. The hard seeded nature of this legume makes it well adapted to crop rotation systems [4]. Currently, serradella is the most widely sown pasture in Western Australia and has proven to be a highly productive legume with high nutritive value [4].

The strains of lupin-nodulating Bradyrhizobium that also nodulate seradella are unusual since they have the capacity to establish symbioses with Mediterranean derived herbaceous and crop legumes endemic to the cool climatic regions of the world. Before the 1990s, the commercial inoculant for serradella (Ornithopus spp.) in Australia was Bradyrhizobium sp. strain WU425, however during the breeding and evaluation of well adapted cultivars of 0 . sativus, it was revealed that WSM471 produced $15 \%$ more biomass with this legume than did WU425 [5]. Strain WSM471 was isolated from nodules of $O$. pinnatus collected in Western Australia, in 1982, although it was almost certainly accidentally introduced to Australia [6]. Because of its superior capacity to fix nitrogen with $O$. sativus relative to other strains of Bradyrhizobium, strain WSM471 was released as a commercial inoculant for this legume in Australia in 1996 [7] and remains in current usage. This strain is also the commercial "back-up" for inoculation of lupins in Australia. Here we present a summary classification and a set of general features for Bradyrhizobium sp. strain WSM471 together with the description of the complete genome sequence and its annotation.

\section{Classification and general features}

Bradyrhizobium sp. strain WSM471 is a motile, Gram-negative, non-spore-forming rod (Figure 1
Left, Center) in the order Rhizobiales of the class Alphaproteobacteria. It is slow growing, forming colonies within 7-10 days when grown on half Lupin Agar ( $1 / 2 \mathrm{LA}$ ) [8] at $28^{\circ} \mathrm{C}$. Colonies on $1 / 2 \mathrm{LA}$ are white-opaque, slightly domed, moderately mucoid with smooth margins (Figure 1 Right).

Minimum Information about the Genome Sequence (MIGS) is provided in Table 1 . Figure 2 shows the phylogenetic relationship of Bradyrhizobium sp. strain WSM471 in a 16S rRNA sequence based tree. This strain clusters closest to Bradyrhizobium canariense LMG $22265^{\mathrm{T}}$ and Bradyrhizobium japonicum LMG 6138 ${ }^{\mathrm{T}}$ with 99.9\% and $99.5 \%$ sequence identity, respectively.

\section{Symbiotaxonomy}

Bradyrhizobium sp. strain WSM471 was isolated from nodules of Ornithopus pinnatus collected from Oyster Harbour, near Albany, Western Australia (34.98 lat; 117.96 long), in 1982. The purpose of the collection of the nodules that gave rise to WSM471 was to seek strains of nodulating bacteria that might improve the winter nitrogen fixation capacity of the symbiosis with Lupinus angustifolius. This symbiosis seemed to be limited by low winter temperatures, which was later confirmed by Peltzer et al. [22]. Strain WSM471 is highly effective for nitrogen fixation with the grain legumes $L$. pilosus, $L$. angustifolius and $L$. atlanticus, and also the forage legumes 0 . pinnatus, $O$. sativus and $O$. compressus [5,23]. Because WSM471 has a broad range for symbiotic nitrogen fixation across both pulse and forage legumes, and is in commercial usage, it was chosen as a candidate strain for sequencing.
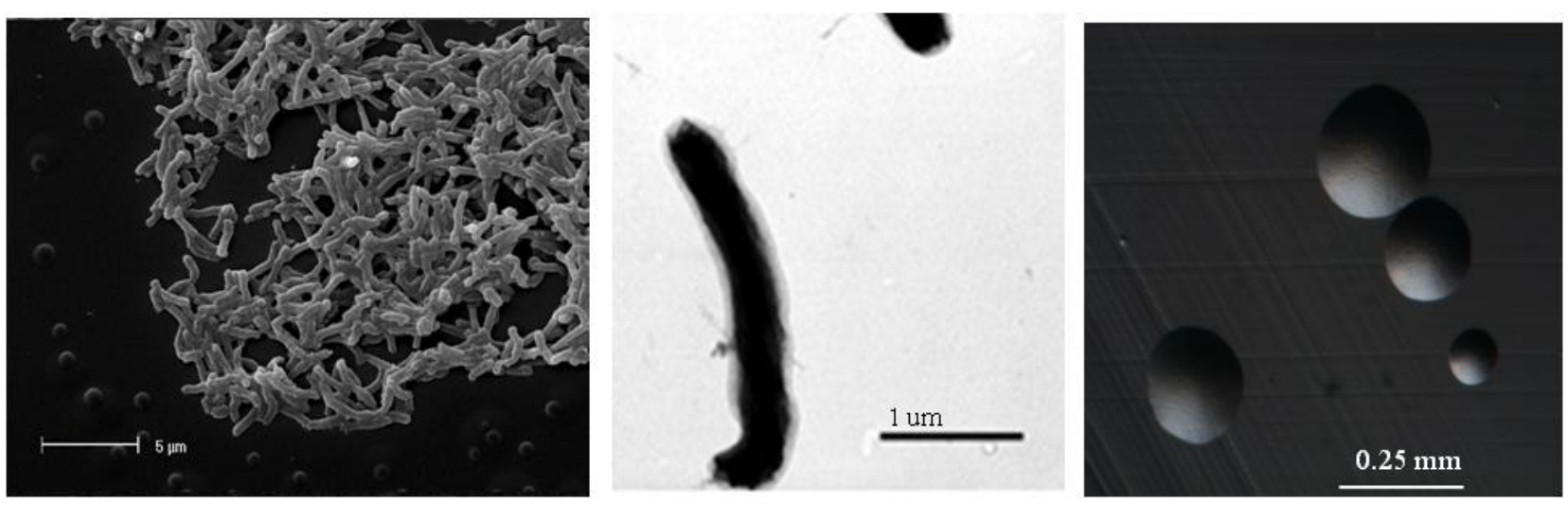

Figure 1. Images of Bradyrhizobium sp. strain WSM471 using scanning (Left) and transmission (Center) electron microscopy as well as light microscopy to visualize colony morphology on a solid medium (Right). 
Table 1. Classification and general features of Bradyrhizobium sp. strain WSM471 according to the MIGS recommendations [9].

\begin{tabular}{|c|c|c|c|}
\hline MIGS ID & Property & Term & Evidence code \\
\hline & \multirow{7}{*}{ Current classification } & Domain Bacteria & TAS [10] \\
\hline & & Phylum Proteobacteria & TAS [11] \\
\hline & & Class Alphaproteobacteria & TAS $[12,13]$ \\
\hline & & Order Rhizobiales & TAS $[13,14]$ \\
\hline & & Family Bradyrhizobiaceae & TAS $[13,15]$ \\
\hline & & Genus Bradyrhizobium & TAS [16] \\
\hline & & Species Bradyrhizobium sp. & IDA \\
\hline & Gram stain & Negative & TAS [16] \\
\hline & Cell shape & Rod & TAS [16] \\
\hline & Motility & Motile & TAS [16] \\
\hline & Sporulation & Non-sporulating & TAS [16] \\
\hline & Temperature range & Mesophile & TAS [16] \\
\hline & Optimum temperature & $28^{\circ} \mathrm{C}$ & TAS [16] \\
\hline & Salinity & Not reported & \\
\hline \multirow[t]{3}{*}{ MIGS-22 } & Oxyg en requirement & Aerobic & TAS [16] \\
\hline & Carbon source & Varied & TAS [16] \\
\hline & Energy source & Chemoorg a notroph & TAS [16] \\
\hline MIGS-6 & Habitat & Soil, root nodule on host & IDA \\
\hline MIGS-15 & Biotic relationship & Free living, symbiotic & IDA \\
\hline \multirow[t]{3}{*}{ MIGS-14 } & Pathog enicity & Non-pathogenic & NAS \\
\hline & Biosafety level & 1 & TAS [17] \\
\hline & Isolation & Root nodule & IDA \\
\hline MIGS-4 & Geographic location & Albany, Western Australia & IDA \\
\hline MIGS-5 & Nodule collection date & 1982 & IDA \\
\hline MIGS-4.1 & Long itude & 117.96 & IDA \\
\hline MIGS-4.2 & Latitude & -34.98 & IDA \\
\hline MIGS-4.3 & Depth & Not recorded & \\
\hline MIGS-4.4 & Altitude & $69 m$ & IDA \\
\hline
\end{tabular}

Evidence codes - IDA: Inferred from Direct Assay; TAS: Traceable Author Statement (i.e., a direct report exists in the literature); NAS: Non-traceable Author Statement (i.e., not directly observed for the living, isolated sample, but based on a generally accepted property for the species, or anecdotal evidence). These evidence codes are from the Gene Ontology project [18]. 


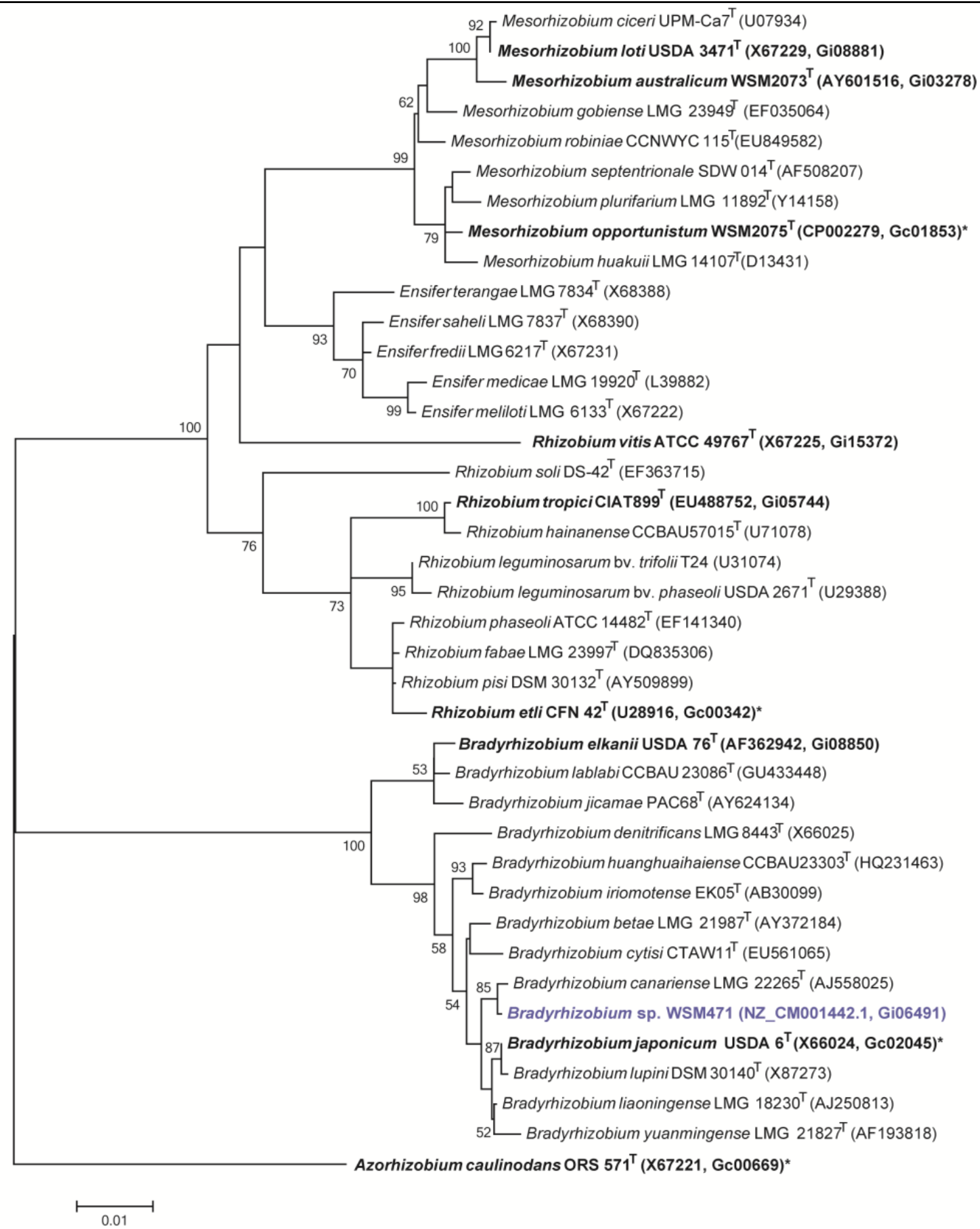

Figure 2. Phylogenetic tree showing the relationships of Bradyrhizobium sp. strain WSM471 (shown in blue print) with some of the root nodule bacteria in the order Rhizobiales based on alig ned sequences of the $16 \mathrm{~S}$ rRNA gene (1,310 bp internal reg ion). All sites were informative and there were no gap-containing sites. Phylogenetic analyses were performed using MEGA, version 5.05 [19]. The tree was built using the maximum likelihood method with the General Time Reversible model. Bootstrap analysis [20] with 500 replicates was performed to assess the support of the clusters. Type strains are indicated with a superscript T. Strains with a genome sequencing project registered in GOLD [21] are in bold print and the GOLD ID is mentioned after the accession number. Published genomes are desig nated with an asterisk. 


\section{Genome sequencing and annotation} information

\section{Genome project history}

This organism was selected for sequencing on the basis of its environmental and agricultural relevance to issues in global carbon cycling, alternative energy production, and biogeochemical importance, and is part of the Community Sequencing Program at the U.S. Department of Energy, Joint Genome Institute (JGI) for projects of relevance to agency missions. The genome project is deposited in the Genomes OnLine Database [21] and an improved-high-quality-draft genome sequence in IMG. Sequencing, finishing and annotation were performed by the JGI. A summary of the project information is shown in Table 2.

\section{Growth conditions and DNA isolation}

Bradyrhizobium sp. strain WSM471 was grown to mid logarithmic phase in TY rich medium [24] on a gyratory shaker at $28^{\circ} \mathrm{C}$. DNA was isolated from $60 \mathrm{~mL}$ of cells using a CTAB (Cetyl trimethyl ammonium bromide) bacterial genomic DNA isolation method [25].

\section{Genome sequencing and assembly}

The genome of Bradyrhizobium sp. WSM471 was generated at the DOE Joint Genome Institute (JGI) using a combination of Illumina [26] and 454 technologies [27]. An Illumina GAii shotgun library which generated $67,039,982$ reads totaling 5,095 $\mathrm{Mb}$ and 1 paired end 454 library with an average insert size of $5 \mathrm{~Kb}$ which generated 397,976 reads totaling $83.7 \mathrm{Mb}$ of 454 were generated for this genome. All general aspects of library construction and sequencing performed at the JGI can be found at the JGI website [25]. The initial draft assembly contained 236 contigs in 2 scaffolds. The 454 Titanium standard data and the 454 paired end data were assembled together with Newbler, version 2.3. The Newbler consensus sequences were computationally shredded into $2 \mathrm{~Kb}$ overlapping fake reads (shreds). Illumina sequencing data was assembled with Velvet, version 1.0.13 [28], and the consensus sequence were computationally shredded into $1.5 \mathrm{~kb}$ overlapping fake reads (shreds). We integrated the 454 Newbler consensus shreds, the Illumina Velvet consensus shreds and the read pairs in the 454 paired end library using parallel phrap, version SPS - 4.24 (High Performance Software, LLC). The software Consed [29-31] was used in the following finishing process. Illumina data was used to correct potential base errors and increase consensus quality using the software Polisher developed at JGI (Alla Lapidus, unpublished). Possible mis-assemblies were corrected using gapResolution (Cliff Han, unpublished), Dupfinisher [32], or sequencing cloned bridging PCR fragments with subcloning. Gaps between contigs were closed by editing in Consed, by PCR and by Bubble PCR (JF Cheng, unpublished) primer walks. A total of 327 additional reactions were necessary to close gaps and to raise the quality of the finished sequence. The estimated genome size is $7.8 \mathrm{Mb}$ and the final assembly is based on $53.8 \mathrm{Mb}$ of 454 draft data which provides an average $6.9 \times$ coverage of the genome and 4,879.9 $\mathrm{Mb}$ of Illumina draft data which provides an average $625.6 \times$ coverage of the genome.

Table 2. Genome sequencing project information for Bradyrhizobium sp. strain WSM471.

\begin{tabular}{lll}
\hline MIGS ID & Property & Term \\
\hline MIGS-31 & Finishing quality & Non-contiguous Finished \\
MIGS-28 & Libraries used & Illumina GAii shotg un and paired end 454 libraries \\
MIGS-29 & Sequencing platforms & Illumina GAii and 454 GS FLX Titanium technologies \\
MIGS-31.2 & Sequencing coverage & $6.9 \times 454$ paired end, Illumina 625.6 \\
MIGS-30 & Assemblers & Velvet1.0.13, Newbler 2.3, phrap 4.24 \\
MIGS-32 & Gene calling methods & Prodigal 1.4, GenePRIMP \\
& Genbank ID & CM001442 \\
& Genbank Date of Release & February 2, 2012 \\
& GOLD ID & Gi06491 \\
& NCBI project ID & 61807 \\
& Database: IMG & 2508501009 \\
& Project relevance & Symbiotic $\mathrm{N}_{2}$-fixation, ag riculture \\
\hline
\end{tabular}




\section{Genome annotation}

Genes were identified using Prodigal [33] as part of the DOE-JGI Annotation pipeline [34] followed by a round of manual curation using the JGI GenePRIMP pipeline [35]. The predicted CDSs were translated and used to search the National Center for Biotechnology Information (NCBI) nonredundant database, UniProt, TIGRFam, Pfam, PRIAM, KEGG, COG, and InterPro databases. These data sources were combined to assert a product description for each predicted protein. Noncoding genes and miscellaneous features were predicted using tRNAscan-SE [36], RNAMMer [37], Rfam [38], TMHMM [39], and SignalP [40]. Additional gene prediction analyses and functional an- notation were performed within the Integrated Microbial Genomes (IMG-ER) platform [41].

\section{Genome properties}

The genome is 7,784,016 nucleotides with $63.40 \%$ GC content (Table 3) and comprised of 1 scaffold (Figure 3a, Figure 3b) of 2 contigs. From a total of 7430 genes, 7,372 were protein encoding and 58 RNA only encoding genes. Within the genome, 274 pseudogenes were also identified. The majority of genes $(74.10 \%)$ were assigned a putative function whilst the remaining genes were annotated as hypothetical. The distribution of genes into COGs functional categories is presented in Table 4.

Table 3. Genome Statistics for Bradyrhizobium sp. strain WSM471.

\begin{tabular}{|c|c|c|}
\hline Attribute & Value & $\%$ of Total \\
\hline Genome size (bp) & $7,784,016$ & 100.00 \\
\hline DNA coding region (bp) & $6,519,740$ & 83.76 \\
\hline DNA G+C content (bp) & $4,935,436$ & 63.40 \\
\hline Number of scaffolds & 1 & \\
\hline Number of contigs & 2 & \\
\hline Total genes & 7,430 & 100.00 \\
\hline RNA genes & 58 & 0.78 \\
\hline rRNA operons & 1 & 0.01 \\
\hline Protein-coding genes & 7,372 & 99.22 \\
\hline Genes with function prediction & 5,506 & 74.10 \\
\hline Genes assig ned to COGs & 5,507 & 74.12 \\
\hline Genes assigned Pfam domains & 5,758 & 77.50 \\
\hline Genes with signal peptides & 834 & 11.22 \\
\hline Genes with transmembrane helices & 1,739 & 23.41 \\
\hline CRISPR repeats & 0 & \\
\hline
\end{tabular}




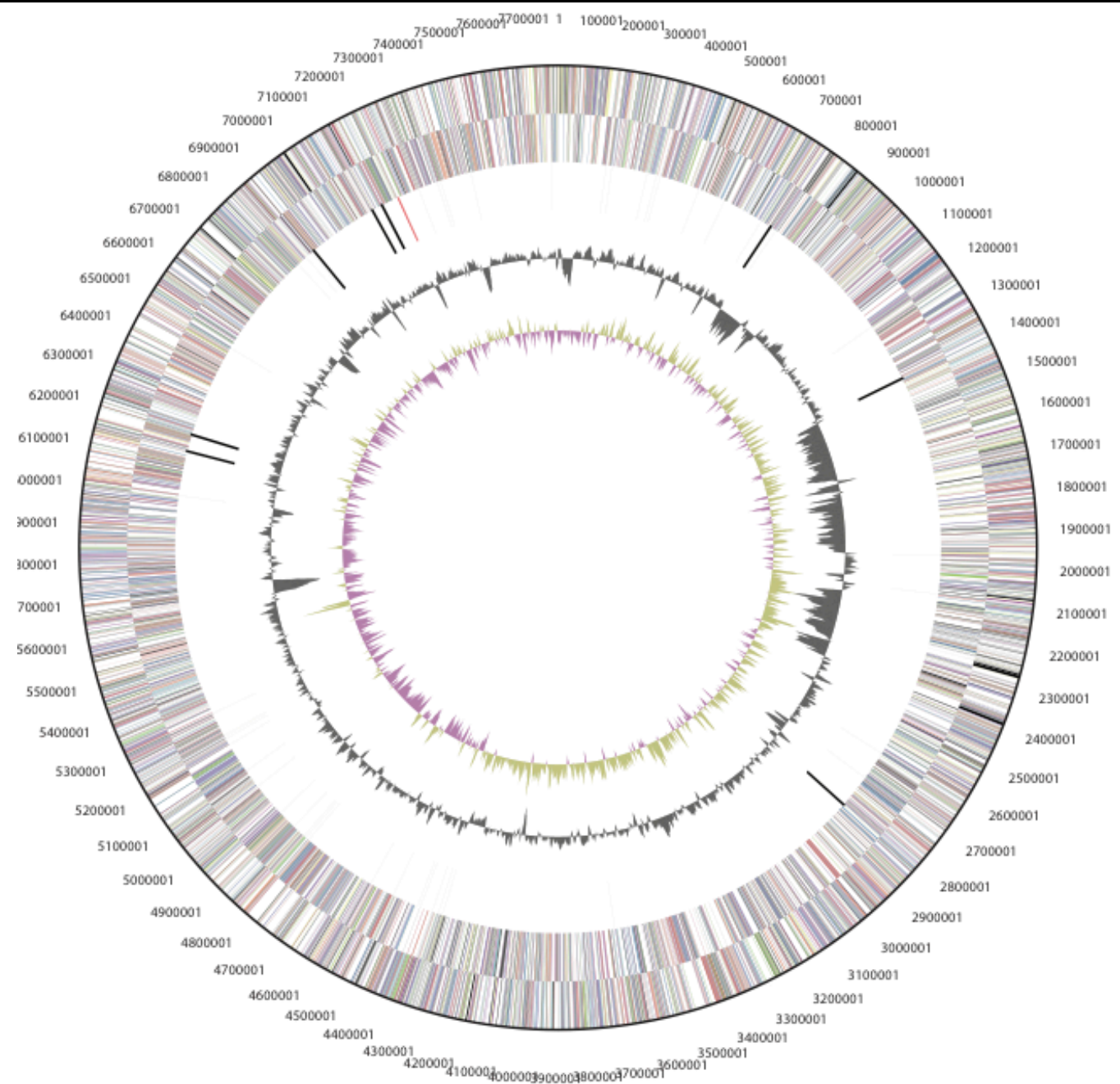

Figure 3a. Graphical circular map of the chromosome of Bradyrhizobium sp. strain WSM471. From outside to the center. Genes on forward strand (color by COG categ ories as denoted by the IMG platform), Genes on reverse strand (color by COG categories), RNA genes (tRNAs g reen, sRNAs red, other RNAs black), GC content, GC skew.

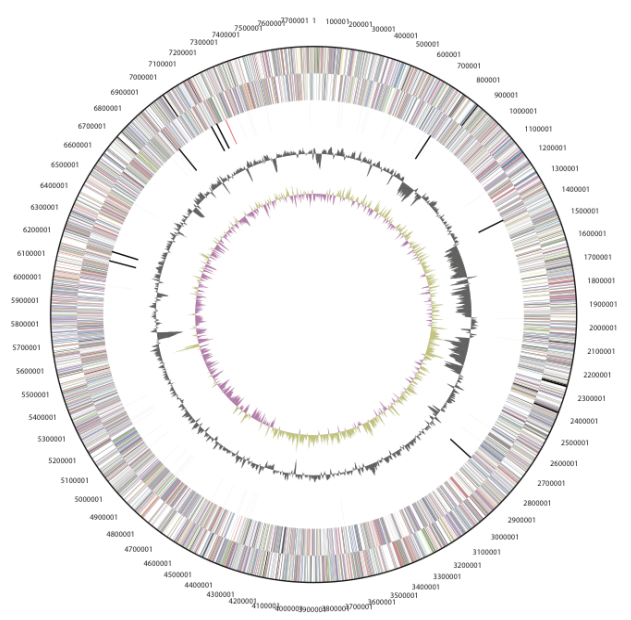

Figure 3b. Graphical circular map of the plasmid of Bradyrhizobium sp. strain WSM471. From outside to the center: Genes on forward strand (color by COG categories as denoted by the IMG platform), Genes on reverse strand (color by COG categories), RNA genes (tRNAs green, sRNAs red, other RNAs black), GC content, GC skew. 
Table 4. Number of protein coding genes of Bradyrhizobium sp. strain WSM471 associated with the general COG functional categories.

\begin{tabular}{crrl}
\hline Code & Value & \%age & Description \\
\hline J & 208 & 3.37 & Translation, ribosomal structure and biogenesis \\
A & 1 & 0.02 & RNA processing and modification \\
K & 395 & 6.41 & Transcription \\
L & 268 & 4.35 & Replication, recombination and repair \\
B & 2 & 0.03 & Chromatin structure and dynamics \\
D & 33 & 0.54 & Cell cycle control, mitosis and meiosis \\
Y & 0 & 0.00 & Nuclear structure \\
V & 85 & 1.38 & Defense mechanisms \\
T & 369 & 5.98 & Signal transduction mechanisms \\
M & 327 & 5.30 & Cell wall/membrane biogenesis \\
N & 121 & 1.96 & Cell motility \\
Z & 1 & 0.02 & Cytoskeleton \\
W & 0 & 0.00 & Extracellular structures \\
U & 102 & 1.65 & Intracellular trafficking and secretion \\
O & 191 & 3.10 & Posttranslational modification, protein turnover, chaperones \\
C & 410 & 6.65 & Energy production conversion \\
G & 406 & 6.58 & Carbohydrate transport and metabolism \\
E & 645 & 10.46 & Amino acid transport metabolism \\
F & 88 & 1.43 & Nucleotide transport and metabolism \\
H & 234 & 3.79 & Coenzyme transport and metabolism \\
I & 335 & 5.43 & Lipid transport and metabolism \\
P & 304 & 4.93 & Inorganic ion transport and metabolism \\
Q & 238 & 3.86 & Secondary metabolite biosynthesis, transport and catabolism \\
R & 770 & 12.49 & General function prediction only \\
S & 634 & 10.28 & Function unknown \\
\hline & 1,923 & 25.88 & Not in COGS \\
\hline
\end{tabular}

\section{Acknowledgements}

This work was perform ed under the auspices of the US Department of Energy's Office of Science, Biological and Environmental Research Program, and by the University of California, Lawrence Berkeley National Laboratory under contract No. DE-AC02-05CH11231, Lawrence Livermore National Laboratory under Contract No. DEAC52-07NA27344, and Los Alamos National Laboratory under contract No. DE-AC02-06NA25396. We grate- fully acknowledge the funding received from the Murdoch University Strategic Research Fund through the Crop and Plant Research Ins titute (CaPRI) and the Centre for Rhizobium Studies (CRS) at Murdoch University. The authors would like to thank the Australia-China Joint Research Centre for Wheat Im provem ent (ACCWI) and SuperSeed Technologies (SST) for financially supporting Moham ed Ninawi's PhD project. 


\section{References}

1. O'Hara GW. The role of nitrog en fixation in crop production. J Crop Prod 1998; 1:115-138. http://dx.doi.org/10.1300//144v01n02 06

2. Herridge DF, Peoples MB, Boddey RM. Global inputs of biological nitrog en fixation in ag ricultural systems. Plant Soil 2008; 311:1-18. http://dx.doi.org/10.1007/s11104-008-9668-3

3. Howieson JG, O'Hara GW, Carr SJ. Changing roles for legumes in Mediterranean ag riculture: developments from an Australian perspective. Field Crops Res 2000; 65:107-122. http://dx.doi.org/10.1016/S0378-4290(99)00081-7

4. Nichols P, Loi A, Nutt B, Snowball R, Revell C. Domestication of new Mediterranean annual pasture leg umes. In: Huyg he C, editor. Sustainable Use of Genetic Diversity in Forage and Turf Breeding: Springer; 2010. p 137-142.

5. Ballard R. Assessment of strains of Bradyrhizobium sp. (Lupinus) for serradellas (Ornithopus spp.). Aust J Exp Agric 1996; 36:63-70.

http://dx.doi.org/10.1071/EA9960063

6. Stepkowski T, Moulin L, Krzyzanska A, Mclnnes A, Law IJ, Howieson J. European origin of Bradyrhizobium populations infecting lupins and serradella in soils of Western Australia and South Africa. Appl Environ Microbiol 2005; 71:70417052. PubMed http://dx.doi.org/10.1128/AEM.71.11.7041$\underline{7052.2005}$

7. Bullard GK, Roughley RJ, Pulsford DJ. The leg ume inoculant industry and inoculant quality control in Australia: 1953-2003. Aust J Exp Agric 2005; 45:12 7-140. http://dx.doi.org/10.1071/EA03159

8. Howieson JG, Ewing MA, D'antuono MF. Selection for acid tolerance in Rhizobium meliloti. Plant Soil 1988; 105:179-188.

http://dx.doi.org/10.1007/BF02376781

9. Field D, Garrity G, Gray T, Morrison N, Seleng ut J, Sterk P, Tatusova T, Thomson N, Allen M, Angiuoli SV, et al. Towards a richer description of our complete collection of genomes and metagenomes "Minimum Information about a Genome Sequence " (MIGS) specification. Nat Biotechnol 2008;

26:541-547. PubMed http://dx.doi.org/10.1038/nbt1360

10. Woese CR, Kandler O, Wheelis ML. Towards a natural system of organisms: proposal for the domains Archaea, Bacteria, and Eucarya. Proc Natl Acad Sci USA 1990; 87:4576-4579. PubMed http://dx.doi.org/10.1073/pnas.87.12.4576
11. Garrity GM, Bell JA, Lilburn T. Phylum XIV. Proteobacteria phyl. nov. In: Garrity GM, Brenner DJ, Krieg NR, Staley JT (eds), Bergey's Manual of Systematic Bacteriology, Second Edition, Volume 2, Part B, Springer, New York, 2005, p. 1.

12. Garrity GM, Bell JA, Lilburn T. Class I. Alphaproteobacteria class. In: Garrity GM, Brenner DJ, Kreig NR, Staley JT, editors. Berg ey's Manual of Systematic Bacteriology. Second ed: New York: Springer - Verlag; 2005, p. 1.

13.Validation List No. 107. List of new names and new combinations previously effectively, but not validly, published. Int / Syst Evol Microbiol 2006; 56:16. PubMed http://dx.doi.org/10.1099/ijs.0.64188-0

14. Kuykendall LD. Order VI. Rhizobiales ord. nov. In: Garrity GM, Brenner DJ, Kreig NR, Staley JT, editors. Bergey's Manual of Systematic Bacteriology. Second ed: New York: Springer - Verlag; 2005. p 324.

15. Garrity GM, Bell JA, Lilburn TG. Family VII. Bradyrhizobiaceae. In: Garrity GM, Brenner DJ, Krieg NR, Staley JT, editors. Berg ey's Manual of Systematic Bacteriology. Volume 2. New York: Springer - Verlag; 2005. p 438.

16. Jordan DC. Transfer of Rhizobium japonicum Buchanan 1980 to Bradyrhizobium gen. nov., a genus of slow-g rowing, root nodule bacteria from leguminous plants. Int J Syst Bacteriol 1982; 32:136139. http://dx.doi.org/10.1099/00207713-32-1-136

17. Ag ents B. Technical rules for biological agents. TRBA (http://www.baua.de):466.

18. Ashburner M, Ball CA, Blake JA, Botstein D, Butler H, Cherry JM, Davis AP, Dolinski K, Dwight SS, Eppig JT, et al. Gene ontology: tool for the unification of biology. The Gene Ontology Consortium. Nat Genet 2000; 25:2 5-29. PubMed http://dx.doi.org/10.1038/75556

19. Tamura K, Peterson D, Peterson N, Stecher G, Nei M, Kumar S. MEGA5: molecular evolutionary genetics analysis using maximum likelihood, evolutionary distance, and maximum parsimony methods. Mol Biol Evol 2011; 28:2731-2739. PubMed http://dx.doi.org/10.1093/molbev/msr121

20. Felsenstein J. Confidence limits on phylogenies: an approach using the bootstrap. Evolution 1985; 39:783-791. http://dx.doi.org/10.2307/2408678

21. Liolios K, Mavromatis K, Tavernarakis N, Kyrpides NC. The Genomes On Line Database (GOLD) in 2007: status of genomic and metagenomic projects 
and their associated metadata. Nucleic Acids Res 2008; 36(Database issue):D475-D479. PubMed http://dx.doi.org/10.1093/nar/g km884

22. Peltzer SC, Abbott LK, Atkins CA. Effect of low root-zone temperature on nodule initiation in narrow-leafed lupin (Lupinus angustifolius L.). Aust J Agric Res 2002; 53:355-365. http://dx.doi.org/10.1071/AR01092

23. Howieson JG, Reeve N, Yates RJ. The selection of effective Bradyrhizobium sp. (Lupinus) for new lupin and serradella species. In: Dracup M, Palta J, editors. Proceedings of the First Australian Lupin Technical Symposium. Perth, Western Australia: Department of Agriculture; 1994. p 270-273.

24. Reeve WG, Tiwari RP, Worsley PS, Dilworth MJ, Glenn AR, Howieson JG. Constructs for insertional mutagenesis, transcriptional signal localization and gene regulation studies in root nodule and other bacteria. Microbiology 1999; 145:1307-1316. PubMed http://dx.doi.org/10.1099/13500872-145$\underline{6-1307}$

25. DOE Joint Genome Institute. http://my.jgi.doe.gov/general/index.html

26. Bennett S. Solexa Ltd. Pharmacogenomics 2004; 5:433-438. PubMed http://dx.doi.org/10.1517/14622416.5.4.433

27. Margulies M, Egholm M, Altman WE, Attiya S, Bader JS, Bemben LA, Berka J, Braverman MS, Chen YJ, Chen Z, et al. Genome sequencing in microfabricated high-density picolitre reactors. Nature 2005; 437:376-380. PubMed

28. Zerbino DR. Using the Velvet de novo assembler for short-read sequencing technolog ies. Current Protocols in Bioinformatics 2010; Chapter 11: Unit 115.

29. Ewing B, Green P. Base-calling of automated sequencer traces using phred. II. Error probabilities. Genome Res 1998; 8:186-194. PubMed http://dx.doi.org/10.1101/gr.8.3.175

30. Ewing B, Hillier L, Wendl MC, Green P. Basecalling of automated sequencer traces using phred. I. Accuracy assessment. Genome Res 1998; 8:175185. PubMed http://dx.doi.org/10.1101/g r.8.3.175

31. Gordon D, Abajian C, Green P. Consed: a graphical tool for sequence finishing. Genome Res 1998; 8:195-202. PubMed http://dx.doi.org/10.1101/gr.8.3.195
32. Han C, Chain P. Finishing repeat regions automatically with Dupfinisher. In: Valafar HRAH, editor. Proceeding of the 2006 international conference on bioinformatics \& computational biology: CSREA Press; 2006. p 141-146.

33. Hyatt D, Chen GL, Locascio PF, Land ML, Larimer FW, Hauser LJ. Prodigal: prokaryotic gene recog nition and translation initiation site identification. BMC Bioinformatics 2010; 11:119. PubMed http://dx.doi.org/10.1186/1471-2105-11-119

34. Mavromatis K, Ivanova NN, Chen IM, Szeto E, Markowitz VM, Kyrpides NC. The DOE-JGl Standard operating procedure for the annotations of $\mathrm{mi}$ crobial genomes. Stand Genomic Sci 2009; 1:6367. PubMed http://dx.doi.org/10.4056/sigs.632

35. Pati A, Ivanova NN, Mikhailova N, Ovchinnikova G, Hooper SD, Lykidis A, Kyrpides NC.

GenePRIMP: a gene prediction improvement pipeline for prokaryotic genomes. Nat Methods 2010; 7:455-457. PubMed http://dx.doi.org/10.1038/nmeth.1457

36. Lowe TM, Eddy SR. tRNAscan-SE: a prog ram for improved detection of transfer RNA genes in genomic sequence. Nucleic Acids Res 1997; 25:955964. PubMed

37. Lagesen K, Hallin P, Rodland EA, Staerfeldt HH, Rog nes T, Ussery DW. RNAmmer: consistent and rapid annotation of ribosomal RNA genes. Nucleic Acids Res 2007; 35:3100-3108. PubMed http://dx.doi.org/10.1093/nar/g km160

38. Griffiths-Jones S, Bateman A, Marshall M, Khanna A, Eddy SR. Rfam: an RNA family database. Nucleic Acids Res 2003; 31:439-441. PubMed http://dx.doi.org/10.1093/nar/gkg 006

39. Krogh A, Larsson B, von Heijne G, Sonnhammer EL. Predicting transmembrane protein topology with a hidden Markov model: application to complete genomes. J Mol Biol 2001; 305:567-580. PubMed http://dx.doi.org/10.1006/jmbi.2000.4315

40. Bendtsen JD, Nielsen H, von Heijne G, Brunak S. Improved prediction of sig nal peptides: Sig nalP 3.0. J Mol Biol 2004; 340:783-795. PubMed http://dx.doi.org/10.1016/j.jmb.2004.05.028

41. Markowitz VM, Mavromatis K, Ivanova NN, Chen IM, Chu K, Kyrpides NC. IMG ER: a system for microbial genome annotation expert review and curation. Bioinformatics 2009; 25:22 71-2278. PubMed http://dx.doi.org/10.1093/bioinformatics/btp393 